\title{
Comparison of Collocation of Solar Concentrators with Bean Fields in Mexico and Potato Fields in Canada and Micromechanical Equipment for Their Production
}

\author{
E. Kussul ${ }^{1}$, T. Baydyk ${ }^{1}$, O. Olvera-Tapia ${ }^{2}$ and J. Rodríguez Andrade ${ }^{1}$ \\ 1. Instituto de Ciencias Aplicadas y Tecnología, Circuito Exterior s/n, Cd. Universitaria, Ciudad de México 04510, México \\ 2. Centro de Investigación de Ingeniería y Ciencia Aplicada, Universidad Autónoma del Estado de Morelos, Cuernavaca 62209, \\ México
}

\begin{abstract}
There is an increased interest in renewable forms of energy across the world, with solar energy being one of the most promising forms. Over the last couple of years, we have developed the MET (MicroEquipment Technology). As an application of the MET, we selected the task of production of solar concentrators. Different types of solar concentrators with flat mirrors were developed and prototypes of these solar concentrators (approximately $1 \mathrm{~m}$ in diameter) were made. The proposed solar concentrators were developed on the basis of concentrators patented in Mexico, Spain, and USA. It may be possible to install these concentrators on horizontal roofs of buildings. However, installing them on agricultural fields has become the new trend. As an example, we propose to use them in the potato fields in Canada to obtain dual advantages such as for electrical energy generation and for the minimal loss of agricultural harvest. The second example was analyzed for bean fields, in Mexico. In this paper, we describe the main results in regard to microequipment development for solar concentrator production, several prototypes of solar concentrators with flat mirrors and their co-location and agricultural fields.
\end{abstract}

Key words: MET, microcomponents, solar concentrators, flat mirrors, bean fields, potato fields.

\section{Introduction}

The main aim of this work is to describe the collocation of solar concentrators with bean fields in Mexico and potato fields in Canada. The type of solar concentrator is described in detail in Ref. [1]. For solar concentrator production, we propose the use of MET (MicroEquipment Technology) [2, 3]. Compared to the MEMS (Micro Electro Mechanical Systems) [4], for example, the MET permits applications with different types of materials and permits us to produce $3 \mathrm{D}$ components. In Fig. 1, we present the relative position of MET (as MICRO/MESO scale manufacturing) compared with other types of production (MEMS, NEMS, etc.).

The precision of machining was previously evaluated in 1983 [5]. The author had provided a

Corresponding author: Ernst Kussul, Ph.D., professor, research fields: micromechanics and solar energy. prognosis till 2000-2010 (Fig. 2). However, the author's analysis did not include the microequipment in it. In the case of microequipment, the precision of the equipment is related with the size of machining. Therefore, by producing micromachining, better precision can be obtained in comparison with normal or super precision machining.

The main idea behind MET is to produce newer generations of microequipment with ever decreasing overall sizes [2, 3]. In Fig. 3, we present the generations of MET.

The evaluation of microequipment parameters is described in detail in Precision Engineering [6]. We have utilized the MET advantages to produce different components of solar concentrators.

MET was developed by scientists from Ukraine and Mexico [2, 3]. With every generation, the size decreases by a factor of approximately two. 


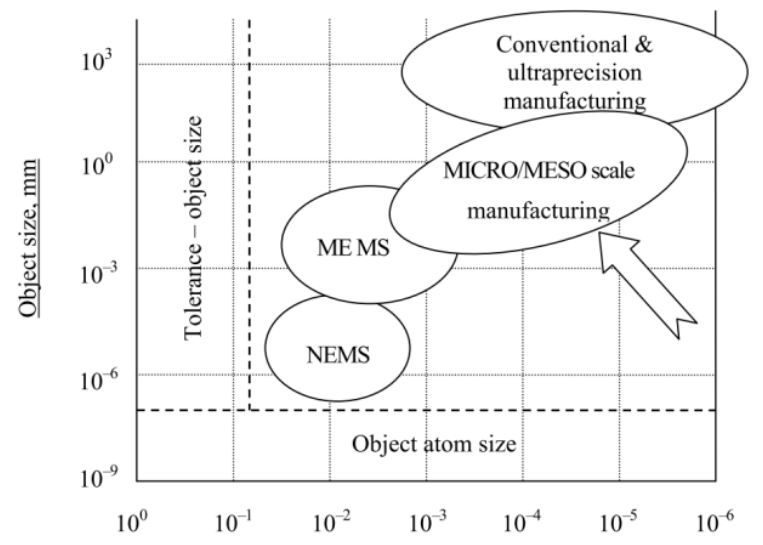

Fig. 1 Domains of dimensions/precisions in micro manufacturing.

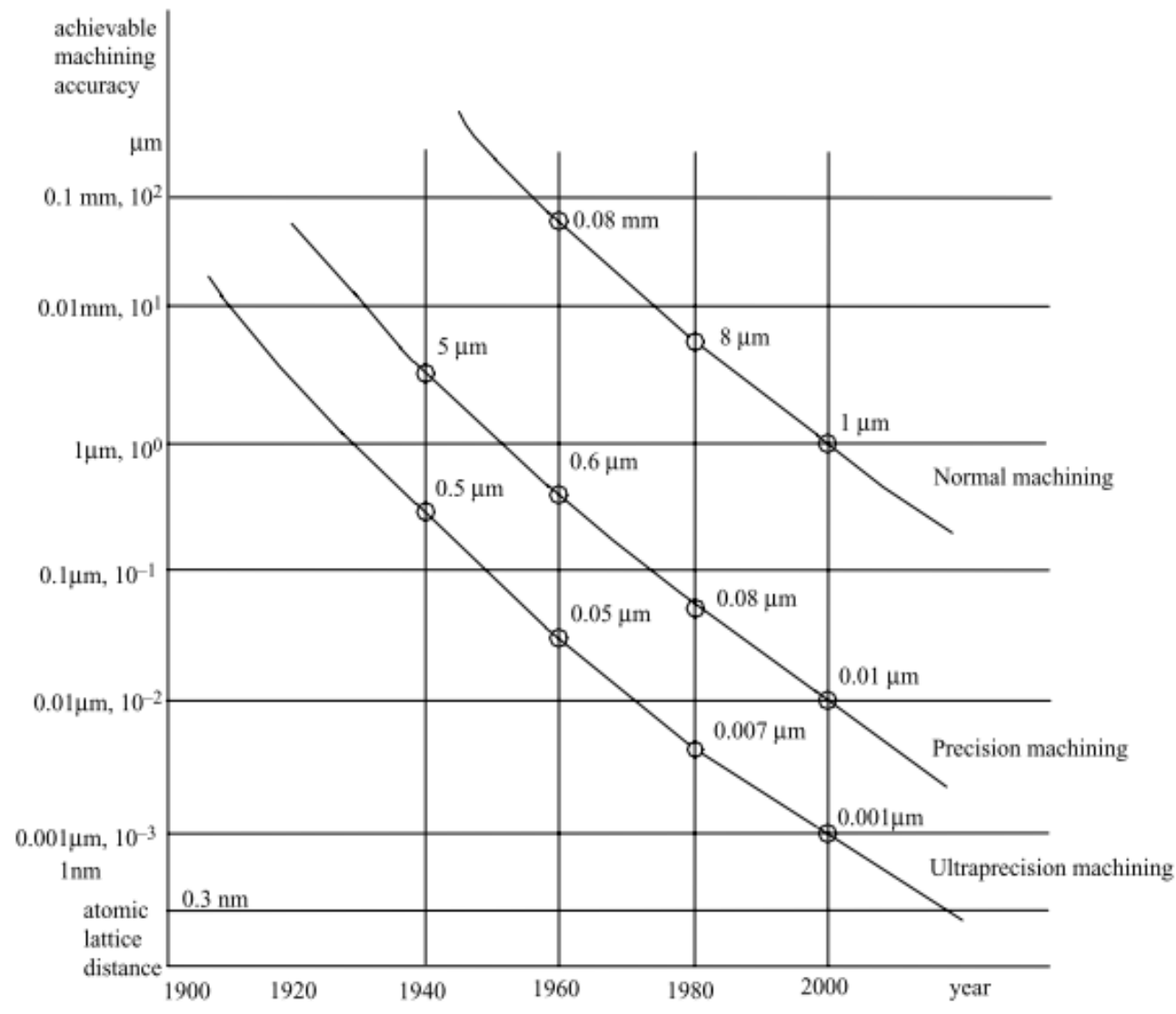

Fig. 2 Curve of machining presicion [5]. 


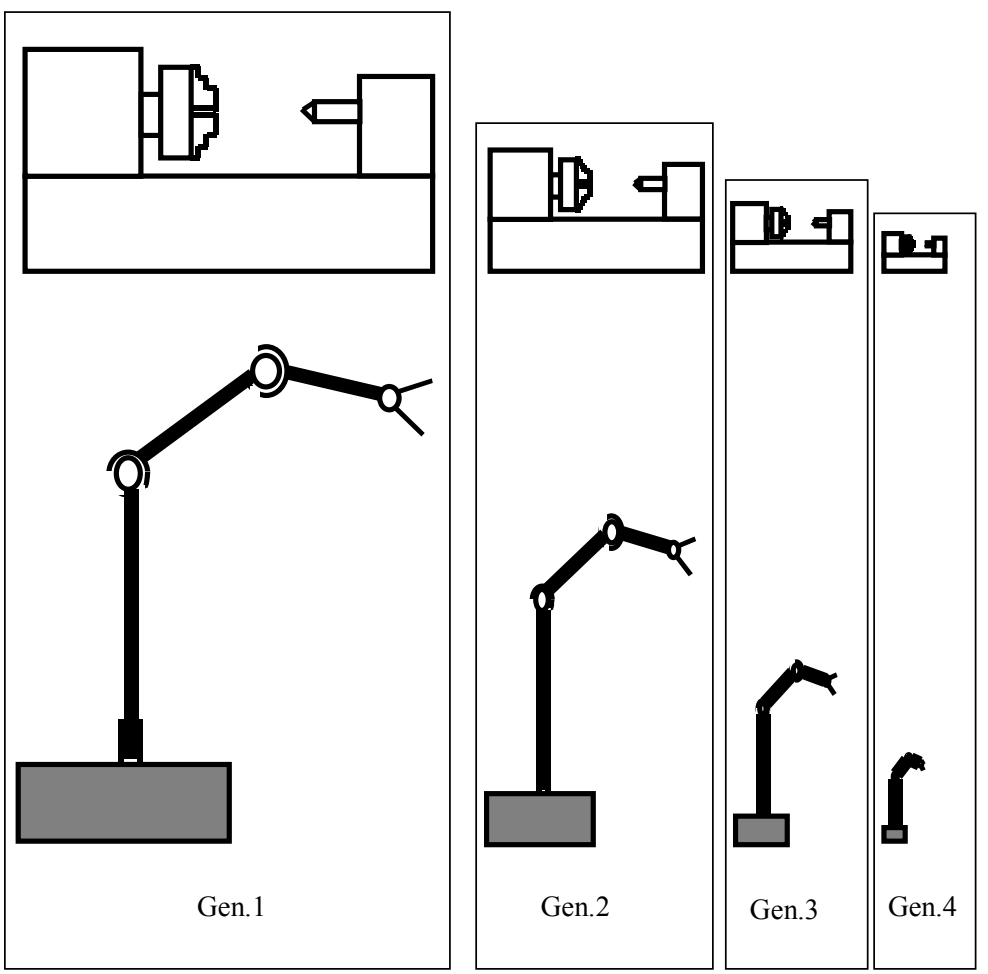

Fig. 3 MET, equipment generations [2, 3].

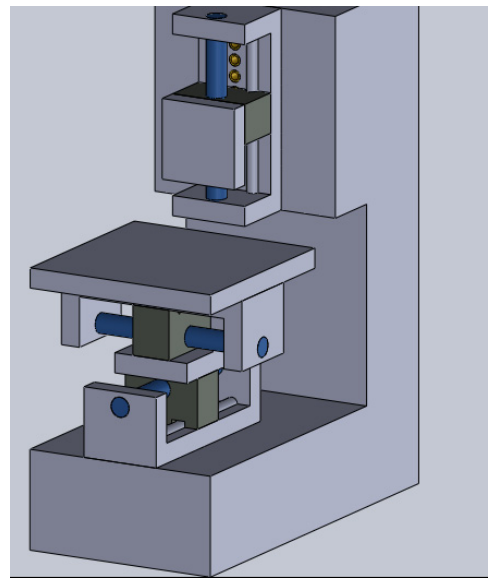

Fig. 4 MicroCNC.

In Fig. 4, we present different projections of the microCNC [7].

To control the actuator position, we use micromotors with a gear box. The prototype is presented in Fig. 5.

In Fig. 6, we present the equipment of the first generation.

Using this microequipment, we have produced different types of microcomponents. In Fig. 7 we present the different types of microcomponents produced using MET. Fig. 7c shows the microrings for the microfilter that was produced for air cleaning.

Triangular flat mirrors, with a side length of $18 \mathrm{~mm}$, were manufactured as a microcomponent, examples of which are shown in containers in Fig. 8. In the following section, we will describe the solar concentrators that were developed using the triangular flat mirrors.

We propose the use of the solar concentrators in the bean fields in Mexico or in potato fields in Canada. Firstly, we describe the bean fields in Mexico. 
Comparison of Collocation of Solar Concentrators with Bean Fields in Mexico and Potato Fields in Canada and Micromechanical Equipment for Their Production

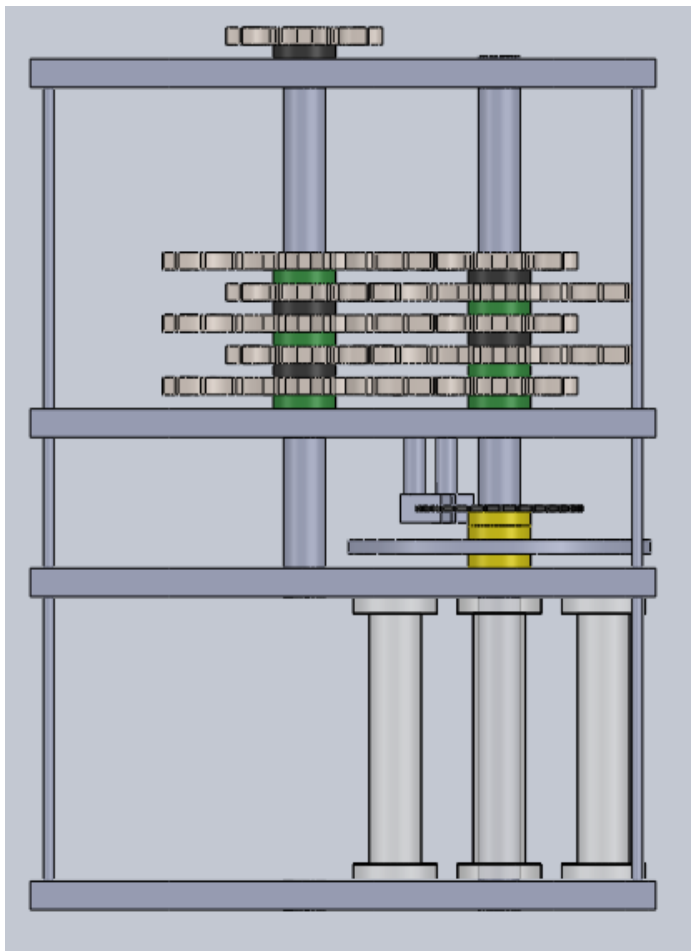

Fig. 5 Micromotor with gear box.
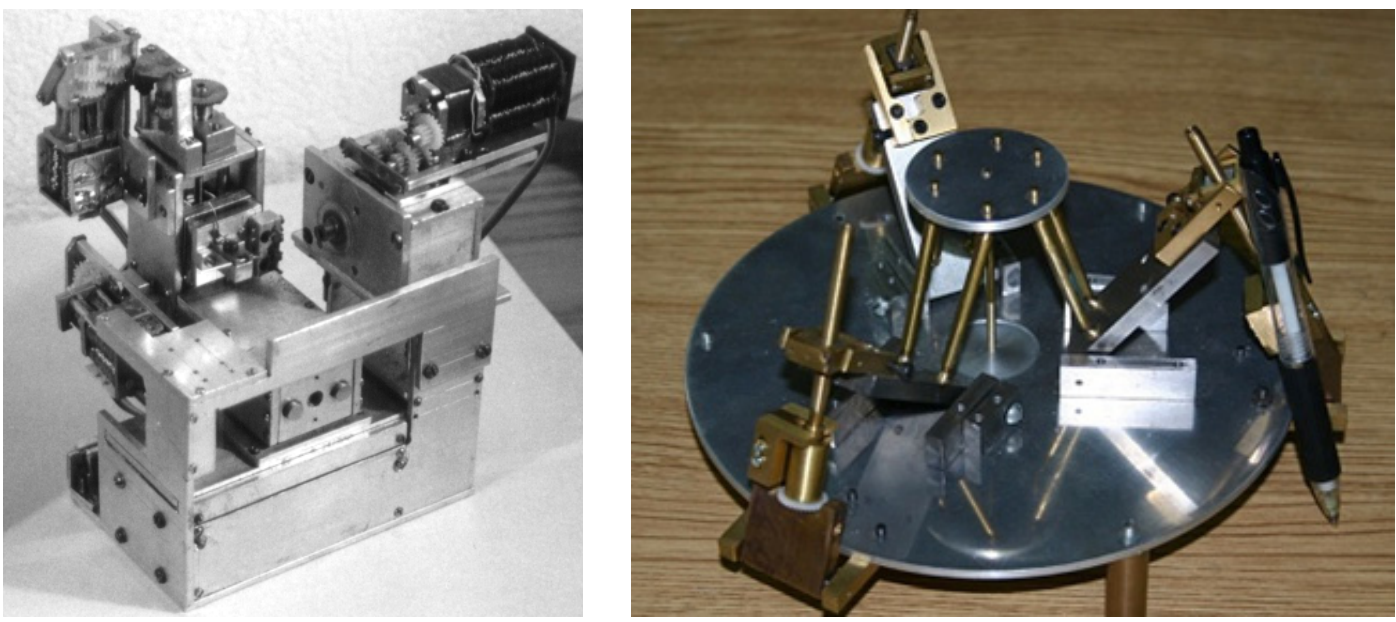

Fig. 6 First generation microequipment.

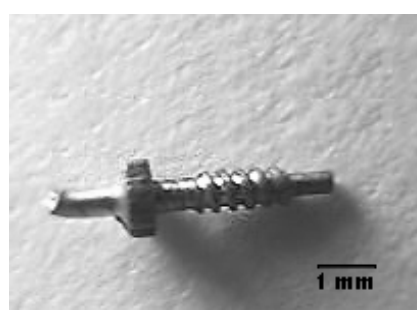

(a)

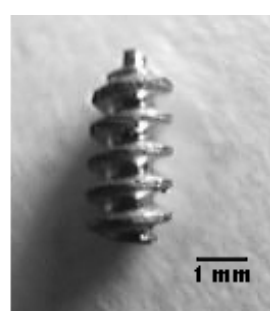

(b)

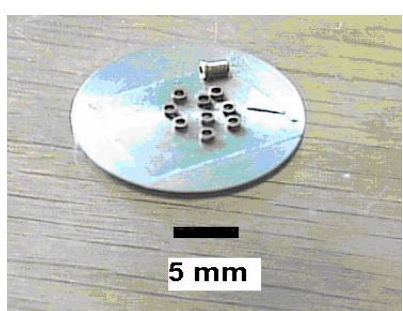

(c)

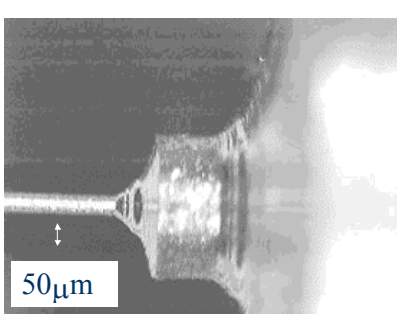

(d)

Fig. 7 The microcomponents produced with MET. 

Canada and Micromechanical Equipment for Their Production

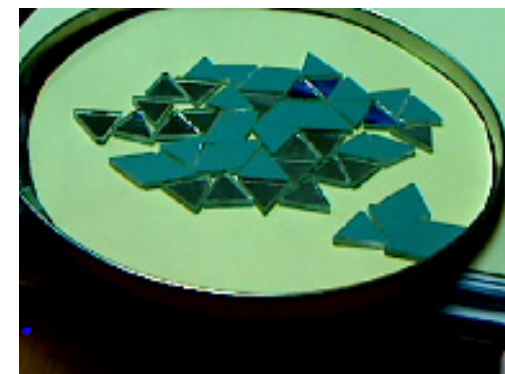

(a)

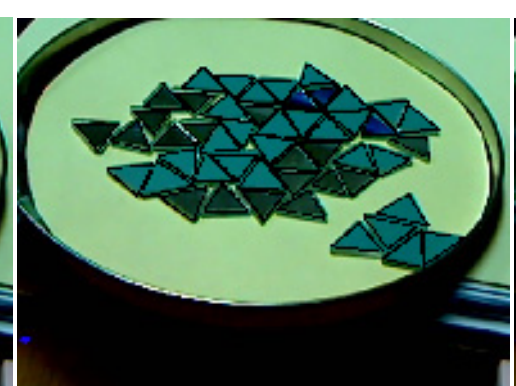

(b)

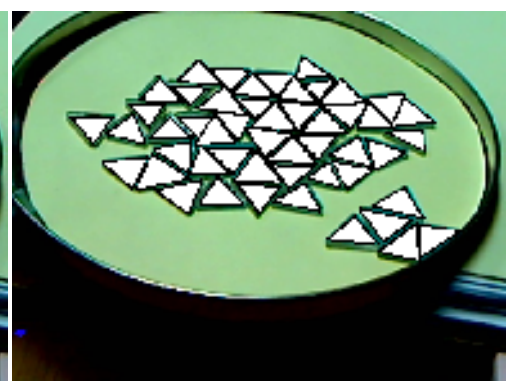

(c)

Fig. 8 Triangular flat mirrors for computer vision recognition. $\mathrm{a}$-initial image; $\mathrm{b}$ —-image with borders; $\mathrm{c}$ - marked images.

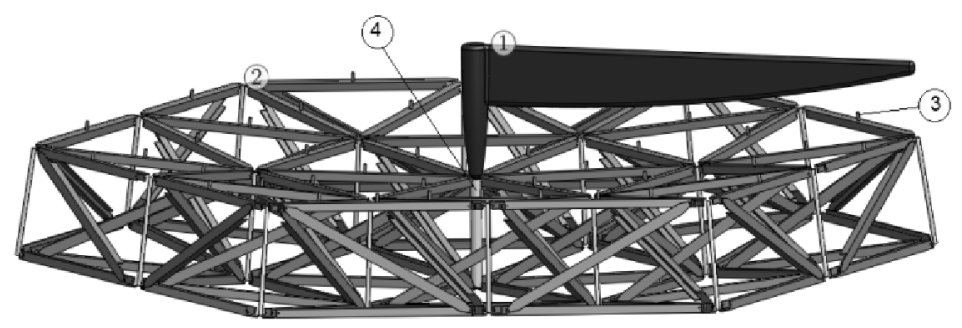

(a)

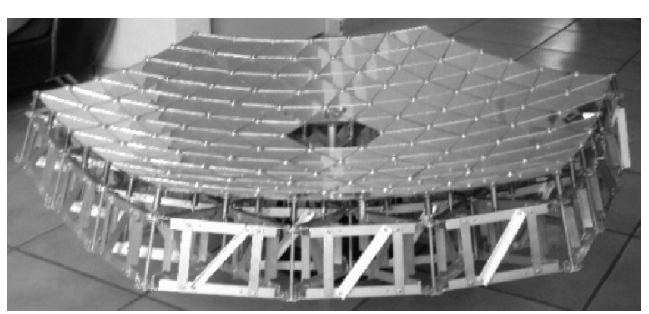

(b)

Fig. 9 Design and prototype of solar concentrator.

$a$ - solar concentrator design, $b$ - solar concentrator prototype.

In Mexico, it is possible to obtain two or three harvests in the year. We propose to collocate solar concentrators between the rows that are to be harvested.

The design and prototype of the solar concentrator with triangular flat mirrors are presented in Fig. 9.

The prototype contains bars and nodes that can be produced with MET technology. The bars were made from aluminum, and every node contains a screw to adjust the mirror height. For this process, we realized the need to install a parabolic gauge in the central tube (Fig. 9a). Every screw was adjusted until they were contacted with the gauge. Using the flat triangular mirrors, we approximated the parabolic surface of the solar concentrator. To minimize the cost of solar concentrator production, we must introduce automation to the manufacturing process.

\section{Design of Agricultural Fields}

In literature, different methods of collocation are described [1, 8-10]. The main idea is to collocate the solar PV with agricultural fields; we

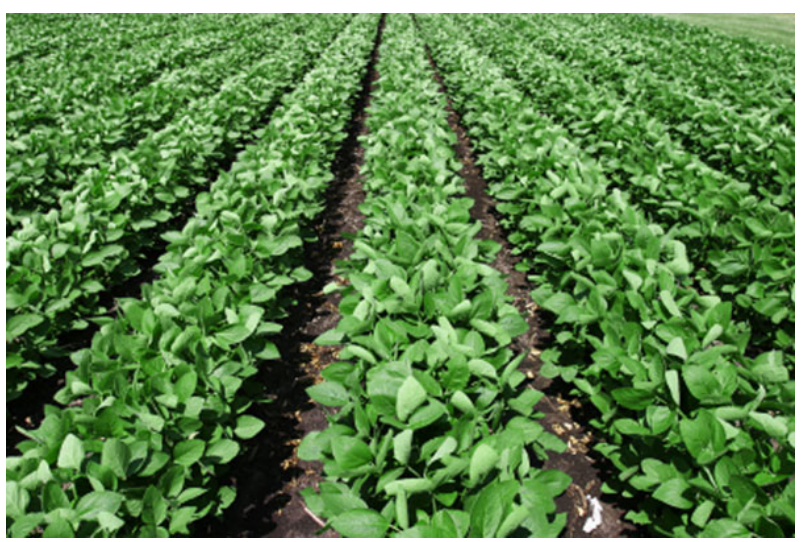

Fig. 10 Grown soy bean field [11].

propose to collocate the parabolic dish solar concentrators with bean fields.

In Fig. 10, the bean field in Campeche, Mexico is presented [11].

The plant has small leaves upon initial growth so the distance between the rows of plants is large. This space can be used to collocate the solar concentrators, whereby the shadows of these concentrators fall between the rows.

To collocate the solar concentrators with an agricultural field, it is necessary to develop a special 


\section{Comparison of Collocation of Solar Concentrators with Bean Fields in Mexico and Potato Fields in Canada and Micromechanical Equipment for Their Production}

structure, as presented in Fig. 11 [12].

It is clear that the distance between combs is sufficiently large and therefore, it is possible to use this space for the solar concentrators.

The position of the parabolic solar concentrators is calculated so that the shade of the solar concentrators is located in the space between the rows where green crop is not present and solar energy may be used without trouble (Fig. 11).

In Fig. 12, we demonstrate only two concentrators. When the crop is mature and the concentrators are too large for the inter-row space (Fig. 12), the concentrators are removed so practically no shade is produced (Fig. 11). Not only the solar concentrators but also the horizontal bars can be removed.

In Mexico, agricultural activity begins from the fourth month, terminating at the tenth or eleventh month. So, during these seven months, solar concentrators can be used. However, it is during the first five months that the solar concentrators can be used easily between the rows of harvest. During this time, the plants are absent and do not demand sunlight. For the final two months, the plants are fully grown and need sunlight. In this case,

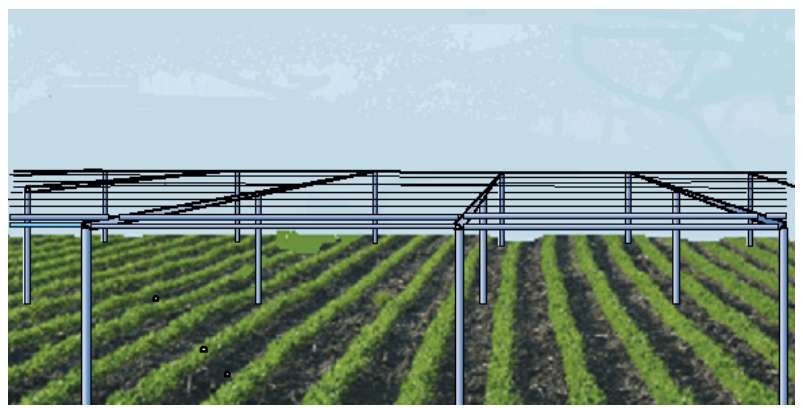

Fig. 11 Structure for solar concentrators [12].

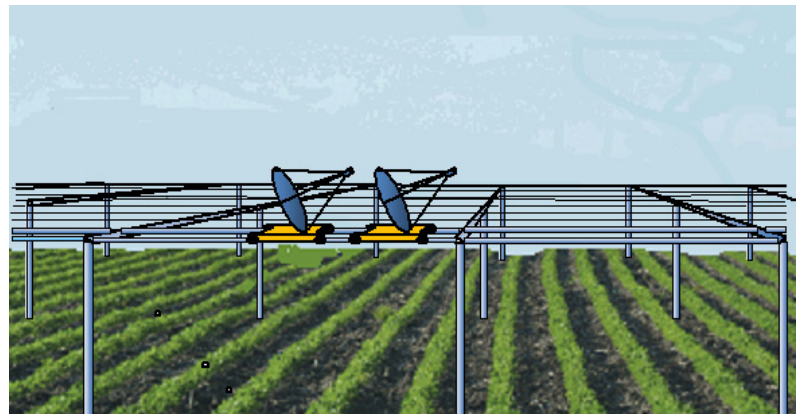

Fig. 12 Structure of collocation of solar concentrators with agricultural fields. the solar concentrators must be removed from the field and stored nearby. From November to April, the entire field can be used for the solar concentrators.

Fig. 13 shows the extent of agricultural activity during the twelve months of the year.

The times of harvest correspond to the greyscale rectangles shown in Fig. 14.

The maximum number of solar collectors can be placed in the field during the period from November to April (Fig. 12). When agricultural activity recommences in the period from April to November, there may be two or three harvests; therefore, we take into consideration three harvests throughout the year (Fig. 14).

Each harvest is divided into two periods. The first period is for when the plants are small and solar concentrators can be used (Fig. 12), while the second period is when the plants are mature. During the second period all concentrators are removed (Fig. 11).

Secondly, we analyze the situation with potato fields in Canada, which is a northern country and has only one harvest per year

Fig. 15 presents one of the potato fields we chose.

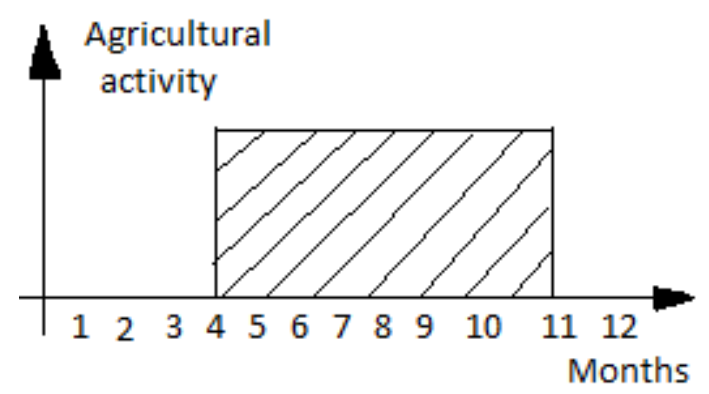

Fig. 13 Extent of agricultural activity.

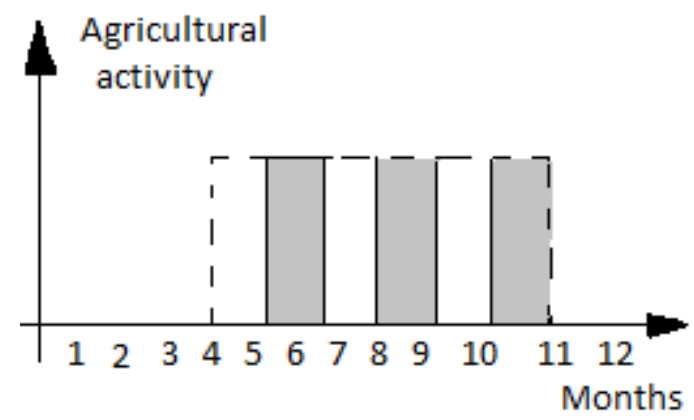

Fig. 14 Three harvests over a period of 12 months. 

Canada and Micromechanical Equipment for Their Production

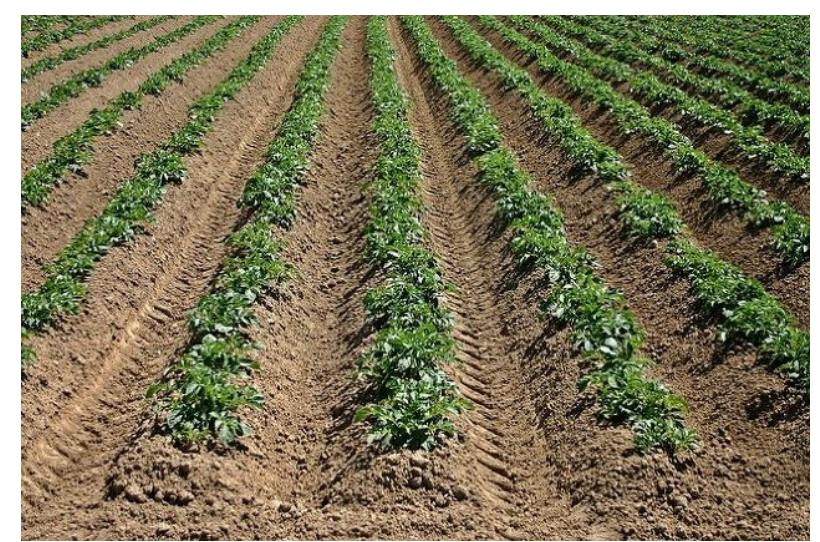

Fig. 15 Initial stage of potato field [16].

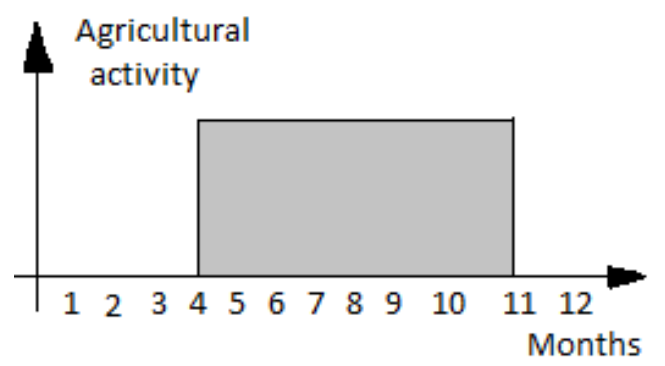

Fig. 16 Agricultural activity.

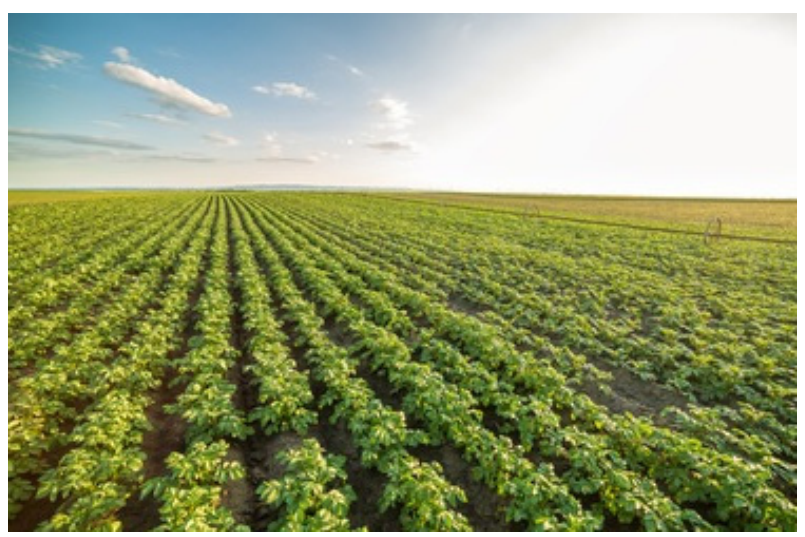

Fig. 17 Potato field in medium stage [17].

The agricultural activity exists between April and September. From October till April there is no agricultural activity present; this period is characterized by rain and snow that is not good for the generation of electricity by solar concentrators. Although it is possible to use them, the efficiency, however, will be not very high. Thus, the best period for solar concentrators is from March to November (Fig. 16). For example, in Ontario, the potato planting season begins in April-May [13]. The harvesting season begins in July (Fig. 17) and runs through the fall [13].
It is possible to collocate between rows on the horizontal lines using the solar concentrators installed above the field. A detailed description of the installation can be found in Refs. [14, 15].

\section{Conclusion}

We propose the use of MET for the manufacture of solar concentrators as this technology permits us to produce different types of microcomponents. The solar concentrators can be collocated with agricultural fields, specifically bean fields in Mexico. We proposed to use them in potato fields in Canada to obtain dual advantages in terms of electrical energy generation and for the minimal loss of agricultural harvest. We described the main results in microequipment development for solar concentrator production. The results of an investigation on collocation methods for the minimal loss of agricultural harvest are described.

\section{Acknowledgements}

This work was partly supported by the project PAPIIT IT100817.

\section{References}

[1] Kussul, E., et al. 2017. "Co-location of Solar Concentrators and Agricultural fields." In Proceedings of the 6th International Conference \& Exhibition on Clean Energy (ICCE 2017), Toronto, Canada, 21-23 August, $1-13$.

[2] Kussul, E., et al. 1996. "Micromechanical Engineering: A Basis for the Low-Cost Manufacturing of Mechanical Micro Devices Using Microequipment." J. of Micromechanics Microengineering 6 (6): 410-25.

[3] Kussul, E., et al. 2002. "Development of Micromachine Tool Prototypes for Microfactories." Journal of Micromechanics and Microengineering 12: 795-813.

[4] Trimmer, W. S., ed. 1996. Micromechanics and MEMD. Classic and Seminal Papers to 1990. IEEE Press, pp. 701.

[5] Taniguchi, N. 1983. "Current Status in, and Future Trends of, Ultraprecision Machining and Ultrafine Materials Processing." CIRP Ann. Manuf. Technol. 32 (2): 573-82.

[6] Kussul, E., et al. 2006. "Scaling Down of Microequipment Parameters.” Precis. Eng. 30 (2): 211-22.

[7] Rodriguez Andrade, J. 2018. Diseño de microcentro de 
maquinado para fabricación de microfiltros de aire, Maestria en Ingenieria Electrica, Opción Instrumentación, 26.01.2018, p. 87.

[8] Macknick, J. 2016. "Overview of Opportunities for Co-Location of Agriculture and Solar PV.” In Clean Energy Economy Conference, Utica, USA, June 16, 21.

[9] Ravi, S., Macknick, J., Lobel, D., Field, C., Ganesan, K., Jain, R., Elchinger, M., and Stottenberg, B. 2016. "Co-location Opportunities for Large Solar Infrastructures and Agriculture in Drylands." Appplied Energy 165: 383-92.

[10] Strom, D., Noble, M., Davis, R., and Macknick, J. 2016. "Co-location of Agriculture and Solar PV, Posted 16.09.2016." Co-location of Agriculture and Solar PV_Fresh Energy Minnesota.html, last visit 17.12.2016.

[11] http://www.2000agro.com.mx/agroindustria/presentan-de manda-por-omisiones-ante-siembra-ilegal-de-soya-gm/.
[12] http://www.hablemosdelcampo.com/hubfs/Imported_Blo g_Media/panoramasoyamexico.jpg.

[13] http://www.ontariopotatoes.ca/growing-potatoes-1.

[14] Kussul, E., et al. 2018. "Micromechanical Equipment for Solar Concentrators Co-located with Bean Fields in Mexico." In Proceedings of the 7th International Conference \& Exhibition on Clean Energy (ICCE 2018), Quebec City, Canada, 6-8 August, 2018, pp. 65-71.

[15] Baydyk, T., et al. 2018. "Evaluation of Solar Concentrators Co-Location and Potato Fields in Canada." In Proceedings of the 7th International Conference \& Exhibition on Clean Energy (ICCE 2018), Quebec City, Canada, 6-8 August, 2018, pp. 25-31.

[16] https://www.hometalk.com/13598891/how-to-grow-potat oes?expand_all_questions $=1$.

[17] shutterstock.com 513225517. 